\title{
HISTÓRIA, MEMÓRIA E LEITURAS DO PASSADO: O QUE AS APROPRIAÇÕES SOBRE DOM PAULO EVARISTO ARNS E O CEL. BRILHANTE USTRA NAS REDES SOCIAIS PODEM NOS ENSINAR?
}

\author{
Sônia Meneses ${ }^{1}$ \\ Egberto Melo $^{2}$
}

Começamos nossa reflexão com um episódio vivenciado por um dos autores em um dos muitos debates realizados na disciplina de Introdução aos Estudos Históricos. Na ocasião discutíamos os jogos de poder nas relações entre memória e esquecimento nas sociedades contemporâneas. Nosso debate girava em torno das provocações feitas por Michael Pollack ${ }^{3}$ em seu conhecido texto "Memória, silêncio, esquecimento". No meio do debate, um aluno fez o seguinte questionamento: "Então um exemplo de memória dos vencedores é o que houve no Brasil sobre a ditadura militar, quando só conhecemos o lado de quem venceu, no caso, a versão dos grupos contra o regime e não o lado dos militares?"

Esta pergunta nos coloca diante de um problema bastante concreto, uma vez que inverte o ponto de observação sobre vencedores e vencidos, pois toma aqueles que consideramos derrotados como vencedores e os perpetradores do golpe como derrotados.

A questão levantada pelo aluno acabou por realçar o que Pollack contempla em seu texto, a exemplo da emergência das memórias daqueles que foram perseguidos e silenciados durante regimes autoritários como o Nazismo e, no nosso caso, a própria Ditadura Brasileira. Pode-se dizer que a partir da década de 90 do século XX, estes personagens puderam expor suas experiências de forma mais incisiva no cotidiano de nossa sociedade.

Por outro lado, realçou a constatação de que a vitória nas guerras das narrativas sobre os episódios para uma parte da população equivale a uma recompensa histórica e, portanto, a uma vitória sobre as derrotas do passado. A pergunta é ainda um exemplo pragmático sobre as tensões e os jogos de acomodação nas "disputas de memória" com as quais nos deparamos e que trouxeram à tona a problemática relação entre história e memória no tempo presente.

Nesse caso, vamos dizer que a ditadura é um exemplo de memória cultural de nossa sociedade isso porque ela tornou-se um acontecimento monumentalizado cuja memória está em constante disputa. Como destaca Aleida Assmann, é aquilo "que supera épocas e é guardado em textos normativos", que é fruto de uma produção historiográfica bastante relevante, mas também tema de diversos produtos como documentários, séries, novelas, etc. Deste modo, é também uma memória comunicativa que, ainda segundo Assmann, é a recordação "que liga três gerações consecutivas e se baseia nas lembranças legadas oralmente". "Essas duas dimensões, normativa e comunicativa, muitas vezes rivalizam de forma radical em nosso cotidiano e, não por acaso, na fala do aluno vemos horizontalizadas as dimensões da história e da memória compreendidas como conceitos similares.

Ou seja, para ele, a memória "comunicativa" sobre o episódio se confunde com a construção "normativa" do conhecimento sobre o acontecimento. Assim, venceu quem controla os relatos do período nos quais predominam a produção acadêmica e também parte significativa da grande mídia. Sua fala nos indica a importância de compreendermos as nuances das apropriações dos acontecimentos históricos no tempo presente, ao mesmo tempo em que nos apresenta os olhares do

\footnotetext{
${ }^{1}$ Profa. Dra. da Universidade Regional do Cariri-URCA. Estuda História Pública, Tempo Presente, História e Mídias. Essa pesquisa é um extrato do projeto de Produtividade do CNPq. Imprensa, leitores e internautas: os embates pela memória sobre ditaduras na América Latina nos jornais Folha de São Paulo e La Nación. Neste artigo, são problematizadas algumas questões sobre tensões da memória recente no Brasil em parceria com o Prof. Dr. Egberto Melo.

${ }^{2}$ Prof. Dr. da Universidade Regional do Cariri-URCA. Ensino de História, Formação de Professor, Tempo Presente, História e Sensibilidades.

${ }^{3}$ POLLACK, Michael. Memória, silêncio e esquecimento. Estudos Históricos. Rio de Janeiro, v. 2. n. 3, 1989, p. 3-15.

${ }^{4}$ ASSMANN, Aleida. Espaços da recordação: formas e transformação da memória cultural. Campinas: Ed. da Unicamp, 2011, p. 17.
} 
sujeito comum para tais ocorrências, posto que um estudante de primeiro semestre de um curso de história ainda efetiva, de maneira intensa, representações que circulam em seu contexto social $e$ cultural, no qual a escola de Educação Básica tem muitas dificuldades em problematizar tais eventos, considerando as diversas obrigações curriculares que precisa cumprir.

Nesse cenário, parece-nos pertinente afirmar que a temática da ditadura militar e do intervencionismo se tornaram questões pulsantes para o Brasil no tempo presente. Podemos elencar várias linhas explicativas sobre esse fenômeno, que certamente teve um grande impulso devido ao acirramento político no qual o país mergulhou a partir de 2013, uma constatação, sobretudo, quando acompanhamos os debates desencadeados sobre os regimes militares em redes sociais. Deste modo, podemos dizer que este é um acontecimento exemplar de história pública, posto que suas elaborações transpõem em muito o universo acadêmico e historiográfico.

Embora as narrativas historiográficas apontem para certo consenso sobre o período, ao defini-lo como um regime autoritário que cerceou direitos, que matou e torturou, dentre outros episódios dramáticos que lhe são vinculados, é inconteste que uma significativa parcela da população brasileira tem uma posição divergente de tais narrativas. Neste sentido, é fundamental compreendermos como essas apropriações ordinárias são ensejadas no cotidiano.

Ao nos determos mais profundamente ao questionamento feito pelo aluno logo o começo do artigo, encontraremos nele o resultado de séries discursivas que nas últimas décadas foram responsáveis por construir os sentidos dissonantes sobre os regimes ditatoriais, tanto no Brasil como em outros países da América Latina, a ponto de, numa dimensão pragmática, perderem-se as compreensões sobre vencedores e vencidos nas disputas sobre o episódio.

Tentaremos abordar aqui um aspecto complexo nesse processo: as apropriações do sujeito ordinário, tal qual compreendeu Certeau, sobre esses episódios a partir de seu contato com conteúdos produzidos pela grande mídia e nas redes sociais. Essa investigação terá como base matérias postadas em redes sociais na página do jornal Folha de São Paulo, no Facebook. Escolhemos textos que tiveram uma ampla repercussão na página do jornal e que dizem respeito às homenagens a dois personagens icônicos do período, sobretudo por suas posturas totalmente opostas: o Cardeal Emérito de São Paulo, Dom Paulo Evaristo Arns - uma das principais vozes contra o regime militar no país e no exterior -, e o Cel. Brilhante Ustra - um reconhecido torturador durante a ditadura militar brasileira.

Nosso objetivo é pensar como a memória e a história são evocadas e o quanto se relacionam às imagens dos dois personagens; esta é também uma reflexão sobre os processos de construção da consciência história no país, uma vez que pretendemos entender como homens e mulheres comuns operaram com conceitos e categorias de reflexão sobre seu próprio passado.

Antes de passarmos aos elementos específicos tratados nesse artigo, esclareceremos um pouco sobre os caminhos percorridos pela pesquisa. Como estamos tratando de uma abordagem de registros relativamente nova, acreditamos ser salutar partilhamos alguns dos desafios para quem se aventura numa pesquisa com materiais tão fluidos como falas e produtos que se realizam apenas no espaço volátil das redes sociais.

\section{Pensar o passado na rede do presente}

Nos últimos anos, temos assistido a um fenômeno que modificou drasticamente nossas relações sociais, tanto em termos de comunicação como também nos laços interpessoais. Diversos autores têm se preocupado em refletir sobre como a passagem do século XX para o século XXI nos jogou a uma espécie de sociedade líquida ${ }^{5}$ cujas relações já não são mais, ou não apenas, estabelecidas por vínculos tradicionais.

Sem dúvida, assistimos a uma inflexão nos modos como nos apropriamos das mais diversas informações, como também nas formas como interagimos com elas, notadamente com a presença da Internet e das recentes mídias sociais em nosso cotidiano. Nesse sentido, não se pode negar que tanto nossas relações com o tempo como com o espaço foram alteradas de maneira extremamente significativas, fazendo com que passado e futuro também se submetam a uma espécie de hiperpresente, acionado ininterruptamente através do espaço virtual. Isto posto, a própria história e a

\footnotetext{
${ }^{5}$ Conceito cunhado pelo sociólogo Zygmunt Bauman para se referir, dentre outros aspectos, à volatilidade dos laços e das relações sociais em nossos dias. Cf. BAUMAN, Zygmunt. Vida Líquida. Rio de Janeiro: Jorge Zahar Editor, 2005. 
memória tornaram-se produtos do imediato, alterando as formas como pensamos historicamente.

Dessa maneira, o passado agora não está apenas disponível para ser relembrando, recontado, há também a possibilidade dele ser revisto, revivido através das infinitas formas de registro disponibilizadas em nosso tempo, aqui quero estabelecer uma diferença fundamental entre ocorrência revista e ocorrência rememorada. ${ }^{6}$

O primeiro desafio é, portanto, responder: como lidar com fontes tão fluídas como estas produzidas nas demandas do imediato?

A primeira resposta é tornar esses registros algo viável em termos de análise histórica, na medida em que possam obedecer, minimamente, elementos éticos que garantam a originalidade $e$ a legitimidade das fontes de pesquisa. Pode-se dizer que, em alguma medida, os historiadores de história pública que lidam com materiais de redes sociais são também produtores de fontes, da mesma forma como pensamos o trabalho feito pelos pesquisadores de história oral, quando estabelecem questões aos seus entrevistados e transformam seus depoimentos, através da gravação de som, de imagem $e$ das transcrições, em fontes históricas de pesquisa.

Em um universo quase ilimitado, como o das redes sociais, o trabalho com essas postagens também necessita ser realizado com a produção de acervos específicos a partir de recortes temáticos. $\mathrm{Na}$ realização desse trabalho, estabelecemos três tipos de recortes: a página de um grande jornal na rede social Facebook, no caso o jornal Folha de São Paulo; um termo de busca limitado: "ditadura militar"; e, por fim, um recorte mais específico dentro deste maior: matérias que envolvessem os personagens título do artigo - Dom Paulo Evaristo Arns e o Cel. Brilhante Ustra. A partir daí, construímos um acervo com os materiais diretamente relacionados a essas três linhas de ação.

Como é possível observar, as matérias se limitam aos anos de 2015 e 2016, quando se percebe uma transformação mais clara no tratamento do tema da ditadura militar no tempo presente, uma vez que estes são anos extremamente significativos, pois efetivaram a emergência de debates em torno do tema nas redes sociais. Impulsionada pela corrente de acontecimentos que assistimos - a exemplo do golpe institucional de 2016, do acirramento das rivalidades políticas e das constantes solicitações de intervencionismo -, a temática alçou-se ao primeiro plano das disputas no espaço público.

De tal modo, as questões que trazemos aqui, longe de tentarem dar conta de uma universidade, ou de generalizarem respostas, apresentam problemas do tempo presente relacionados aos usos do passado. Embora o número das matérias seja limitado, a repercussão atingiu uma parcela bastante significativa de leitores, tanto em envolvimento no próprio Facebook como no site do jornal, como mostraremos a seguir.

A escolha do jornal Folha de São Paulo se justifica por vários motivos, mas gostaríamos de ressaltar a forma como este veículo tem uma relação especial com o episódio, seja por seu apoio total nos primeiros anos ou pela forma como soube trabalhar com sua memória, a fim de construir sobre si próprio uma áurea de veículo democrático, em princípios dos anos de 1980, ao se engajar na campanha das Diretas Já. Fundando em 1921, o Jornal sempre esteve alinhado às elites paulistanas, mas nas últimas décadas do século XX se consolidou como um grande jornal de circulação nacional. Pode se dizer que:

Entre a segunda metade dos anos noventa e a primeira década dos anos 2000, o jornal Folha de São Paulo se tornou um dos mais importantes veículos de discussão política do país. O afamado projeto Folha já se havia firmado e, em termos de inserção nacional, poucas referências ainda associavam a história do jornal ao Golpe de 1964. Entre todos os grandes veículos que apoiaram os militares, certamente o Grupo Folha foi o que melhor soube desvincular sua imagem do episódio, tornandose um de seus principais debatedores na primeira década do século XXI. ${ }^{7}$

O Jornal inaugurou sua página no Facebook apenas no ano de 2010 e hoje conta com quase 6

\footnotetext{
${ }^{6}$ MENESES, Sônia. Internet, História e Esquecimento: sobre pensar o passado escrito no universo virtual. Fronteiras: Revista Catarinense de História [online], Florianópolis, n.21, p. 10-26, 2013.

${ }^{7}$ MENESES, Sônia. A Operação Midiográfica - O Golpe de 1964 e a Folha de São Paulo. São Paulo: Intermeios, 2017, p. 181.
} 
milhões de inscritos, embora tenha deixado de postar em sua página em fevereiro de $2018 .^{8}$

$\mathrm{Na}$ América Latina, os grandes grupos de mídia tiveram um papel de protagonismo, tanto na efetivação das ditaduras - pois muitos jornais foram seus apoiadores - como no trabalho para legitimálas. É importante compreendermos o papel desses jornais e grupos de mídias no apoio aos golpes militares na América Latina, porque, mesmo quando eles mudam de postura em relação a esses acontecimentos, há uma reverberação discursiva que permanece em suas páginas e nas apropriações dos leitores bastante difícil de ser rompida. Não por acaso, há constantes cobranças dos leitores sobre tais posturas, tanto no Brasil como em outros países da América Latina. Em alguns momentos esses discursos se voltam contra os próprios periódicos, tornando-se ainda mais conservadores e menos tolerantes que eles, quando por exemplo, os acusam de serem de esquerda por acatarem a denominação de "ditatura" para se referirem a esses acontecimentos.

No Brasil, sobre 1964, os debates se acirraram ainda mais, ganharam mais visibilidade por ocasião da instituição da Comissão da Verdade, instaurada em 2012, bem como pelas reflexões desencadeadas nas efemérides dos 50 anos do episódio, em 2014, e a apresentação dos resultados da referida Comissão. Destaca-se ainda a emergência de vários movimentos de caráter conservador, como aqueles assistidos nas manifestações de oposição ao governo petista, entre os anos de 2014 e 2016. Notadamente, em muitas manifestações a ditadura brasileira foi festejada e continuou aparecendo de forma saudosista em discursos que ganharam as ruas.

Nestes termos, as memórias $e$ as apropriações desse período assumiram centralidade para a compreensão de nossa sociedade, posto que, o retorno de conceitos como "golpe" e "impeachment" à cena pública brasileira nos demonstrou como esse tema ainda desencadeia uma grande demanda de sentidos em nossos dias.

Como explicar, por exemplo, por que uma significativa parcelada da juventude brasileira simpatiza com o regime militar e suas práticas? Num levantamento inicial, por amostragem, sobre os comentários de internautas leitores das matérias da Folha de São Paulo no Facebook, constatou-se que a maioria dos favoráveis ao regime está na faixa etária de 30 a 40 anos, destaca-se ainda uma significativa concentração na faixa dos 50-60 anos, o que já nos dá indício para pensarmos duas gerações distintas.

Ao nos remetermos a um evento como a ditadura militar brasileira, vemos que o acontecimento se tornou uma espécie de pedra de ouro dos últimos debates sobre o passado; através dele, erigiu-se uma incrível produção fragmentada, multifacetária, marcada pela intervenção dos mais variados sujeitos $e$ grupos sociais que fizeram do Golpe de 1964 um espetacular lugar de tensão e disputas. Não que o próprio evento já não se constituísse em uma grande arena de disputas ao longo das últimas décadas. Diversos autores já haviam se preocupado em destacar as tensões em torno do episódio, a exemplo de Aarão Reis ao destacar que:

Sempre quando os povos transitam de uma fase para outra da história, e quando a seguinte rejeita taxativamente a anterior, há problemas de memória, revolvidos por reconstruções mais ou menos elaboradas, quando não pelo puro e simples esquecimento. A sociedade brasileira, depois que aderiu aos valores e às instituições democráticas, enfrenta grandes dificuldades em compreender como participou, num passado recente, da construção de uma ditadura. ${ }^{9}$

Além disso, é preciso compreender que a forma como transitamos de um regime para o outro também diz muito sobre como lidamos com nosso passado recente, especialmente, com os efeitos negativos imposto pela Lei da Anistia brasileira. Pela força da lei, estabeleceu-se uma espécie de esquecimento comandado, construído como necessidade imperiosa para que o país seguisse ao futuro. Portanto, o trabalho de significação do nosso passado, e da própria memória, foi realizado a partir de grandes fissuras e ausências que nos colocaram no futuro, sem enfrentarmos coletivamente aspectos sobre justiça, culpabilidade, crime e punição relacionados ao episódio.

Carolina Bauer chama atenção:

\footnotetext{
${ }^{8}$ Sobre o papel desempenhado pelos meios de comunicação na produção de acontecimentos históricos e, em especial, a atuação do Grupo Folha em relação à ditadura militar, ver MENESES. Sônia. A Operação Midiográfica...

${ }^{9}$ REIS, Daniel Aarão. Ditadura e Sociedade: as reconstruções da memória. In: . . O Golpe e a Ditadura Militar 40 anos depois (1964-2004). Bauru - SP: EDUSC, 2004, p. 49. 
(...) a longa transição brasileira concorreu para a diluição dos procedimentos desumanos de detenção empregados pelo poder estatal, o que culminaria no esquecimento da memória coletiva do terror implantado pela ditadura. O processo de normalização da sociedade e da política brasileiras foi marcado pela interdição do passado. $^{10}$

Pode-se dizer que tais elementos foram cotejados apenas numa dimensão intelectual e, mesmo quando abordados em produtos culturais como filmes, documentários e livros, não tiveram a mesma repercussão como em outros países, a exemplo da Argentina, onde, ao findar o ciclo o último ciclo ditatorial, realizou-se um grande trabalho de reflexão sobre o seu passado, como a instauração da CONADEP ${ }^{11}$ e a divulgação pública do informe Nunca Mas produzido pela comissão.

Marcos Napolitano atenta para o fato de que a memória e as disputas em torno do tema podem ser agenciadas a partir de vários lugares sociais, como instituições político-ideológicas; instituições voltadas à produção e divulgação da memória, como museus, arquivos, etc.; a mídia jornalística impressa, eletrônica e digital; o campo artístico; universidades, escolas; movimentos sociais e culturais. Para o autor, pensar uma memória hegemônica sobre o regime militar passa pela reflexão desses espaços, ressaltando ainda que

A partir da primeira década do século XXI, as redes sociais de internet, sites privados e a blogosfera como um todo são igualmente importantes na disseminação de perspectivas e opiniões sobre o passado. Espaços também pouco estudados, essas redes virtuais de comunicação têm servido como canais mais ou menos legitimados $e$ influentes para posicionamentos sobre o regime militar brasileiro, ainda que pouco produtivos enquanto debate efetivo. Arrisco dizer que eles têm sido particularmente importantes no revisionismo da extrema direita em sua luta contra a memória crítica, hegemônica e legitimada socialmente sobre o regime militar. ${ }^{12}$

É nessa perspectiva que se apresenta o conjunto dessas questões apresentadas nesse artigo. A partir delas, nossa intenção é perceber a emergência dessas narrativas no espaço público, afim de compreender em que medida o passado tem sido mobilizado, muitas vezes, em visões extremadas de direita que negam os próprios processos históricos, assim, começamos por apresentar nossos personagens centrais.

\section{Faces dissonantes: memórias em disputa de Dom Paulo Evaristo Arns e Cel. Brilhante Ustra}

Em 1973, no período mais truculento do regime ditatorial brasileiro, Dom Paulo Evaristo Arns, então arcebispo de São Paulo, criou a Comissão da Justiça e Paz de São Paulo. Aquela era apenas uma das muitas ações encabeçadas pelo religioso contra o regime militar. Nomeado bispo auxiliar da região norte de São Paulo em 1966, Dom Paulo, desde sua chegada na capital paulista, assumiu um dos papéis mais importantes na resistência ao regime. Vindo de um trabalho de dez anos nas comunidades pobres de Petrópolis, no Rio de Janeiro - período narrado por ele como um dos mais felizes de sua vida -, ao chegar a São Paulo continuou seu trabalho voltado às comunidades mais carentes e, dentre elas, passou a ter contato com a realidade dos presídios, em especial o Carandiru $e$ o Tiradentes. Foi nesse último, em 1969, a pedido do Cardeal Agnelo Rossi, que visitou os frades dominicanos que estavam presos, entre eles Frei Betto e Frei Tito. Encarregado de averiguar as condições dos frades naquele local, Dom Paulo conta que encontrou Tito em uma condição lastimável,

\footnotetext{
${ }^{10}$ BAUER, Caroline. A produção de relatórios Nunca Mais na Argentina e no Brasil, aspectos das transições políticas e da constituição da memória sobre a repressão. Cap. disponível em https://www.researchgate.net/publication/228640818, acessado em 10/09/2018.

${ }^{11}$ Comissão Nacional de Desaparecimento de Pessoas. A partir do informe produzido pela Comissão se instituiu um processo de ampla investigação e debate naquela sociedade que, ao contrário do Brasil, criou sobre o tema uma espécie de excesso de memória, tamanha a repercussão, que ainda hoje mobiliza a coletividade.

${ }^{12}$ NAPOLITANO, Marcos. Recordar é vencer: as dinâmicas e vicissitudes da construção da memória sobre o regime militar brasileiro. Antítese, v.8, n.15 esp., p. 9-44, nov. 2015, p. 16.
} 
"esvaindo-se em sangue". Ao relatar o episódio ao Cardeal Agnelo Rossi, teria ouvido dele: "Muito obrigado dom Paulo, (...) mas outros me garantem que não há tortura nas nossas prisões". ${ }^{13}$

Tal experiência ampliou em Dom Paulo Evaristo Arns um desejo crescente de enfretamento às ações dos militares, através do contínuo monitoramento e denuncia da violência realizada pelo Estado. Entre suas ações, destacam-se a criação da citada Comissão de Justiça e Paz e a luta contra o Esquadrão da Morte nos anos de 1960-70, do qual fazia parte um dos principais torturadores do regime, apontado pelo Ministério Público como seu principal líder, o delegado Sérgio Paranhos Fleury. Dom Paulo também realizou diversos atos em defesa de presos políticos e participou da organização de grandes atos como o culto ecumênico em homenagem a Vladimir Herzog, assassinado nas dependências do DOI-CODI em 1975, que reuniu milhares de pessoas, entre estudantes, políticos e intelectuais, inclusive internacionais, a exemplo de Michel Foucault. Dom Paulo, juntamente com o rabino Henry Sobel, realizou o ato, mesmo com todas as ameaças sofridas. Disse Arns em entrevista realizada em 27/06/2002:

Às duas horas da tarde eu me preparava para ir para a catedral. O governador Paulo Egydio, que tinha recebido Geisel na sua casa, mandou dois emissários: o chefe da Casa Civil e o secretário da fazenda, para me convencerem a não ir. Perguntei o porquê, e eles me disseram: "porque a polícia está espalhada em todos os lugares e, a qualquer grito ou movimento, eles têm ordem para atirar". Aí eu disse: o povo não pode nem abrir a boca para gritar e vocês se arrogam o direito de matar? Vou acusar cada um que matar porque em cada janela da praça nós colocamos fotógrafos e eles estão fotografando e filmando tudo. Quem atirar vai ser identificado e eu vou me responsabilizar para que ele receba o castigo justo". ${ }^{14}$

A postura combativa do religioso durante todo o período o tornou uma das principais lideranças na luta pelos direitos humanos no Brasil. Entre fins dos anos 1970 e início dos 1980, coordenou, juntamente com o rabino Henry Sobel e o pastor presbiteriano Jaime Wright, o "Projeto Brasil Nunca Mais", que reuniu centenas de milhares de páginas de documentos referentes ao período ditatorial, sendo seu livro Brasil Nunca Mais ${ }^{15}$ lançado ainda nos anos 80, como uma das denúncias mais contundentes às ações dos militares.

A brevíssima apresentação de algumas ações encabeçadas por Dom Paulo Evaristo Arns tem a função de situá-lo como uma das figuras mais atuantes contra o regime militar e personagem influente na política brasileira em boa parte do século XX e nas primeiras décadas do século XXI. Certamente, suas atividades se estendem muito além do período ditatorial, principalmente, no que diz respeito aos projetos sociais destinados à população carente, como o trabalho com a pastoral carcerária em São Paulo, as Comunidades Eclesiais de Base, dentre muitas outras ações voltadas aos direitos humanos.

Nesse sentido, a percepção sobre sua presença, ou mesmo a falta de informação sobre ela, nos processos políticos recentes do país, perpassa também um conjunto de representações, lembranças $e$ silenciamentos que atingem coletivamente parcelas da população, em especial as mais jovens.

Se Dom Paulo representou um ícone contra o regime, podemos dizer que nosso segundo personagem é seu oposto perfeito, uma vez que, exatamente no mesmo período, impôs sua presença como uma das imagens mais representativa das ações do estado e sua máquina de repressão $e$ aniquilamento da oposição: o Coronel Carlos Alberto Brilhante Ustra. Iniciamos sua apresentação pelo episódio que instaurou sua presença na cena pública do país, em agosto de 1985.

Era a primeira viagem internacional oficial do então presidente recém-empossado José Sarney ao Uruguai. Em sua comitiva oficial, além de vários políticos, estava uma pessoa bastante conhecida no Brasil, sobretudo por seus vários trabalhos como atriz, a naquele momento deputada, Bete Mendes.

Quinze anos depois, era a primeira vez que encontrava uma das figuras mais marcantes de sua

13 ARNS apud DEL PECCHIA. Folha de São Paulo, 14/10/2016. Disponível em https://www1.folha.uol.com.br/poder/2016/12/1840882-dom-paulo-evaristo-arnsicone-progressista-da-igreja.shtml. Acessado em 27/06/2018.

14 ARNS entrevista à Revista SESC São Paulo em junho de 2002, postada em 13/10/2014 https://www.sescsp.org.br/online/artigo/8305_ENTREVISTA+DOM+PAULO+EVARISTO+ARNS. Acessado em 28/06/2018. ${ }^{15}$ ARNS, Paulo Evaristo. Brasil Nunca Mais. São Paulo, Vozes, 1985. 
vida, sobretudo em virtude dos momentos de angústia pelos quais havia passado, quando em 1970, aos 21 anos, estudante universitária e membro da recém-criada Vanguarda Armada Revolucionária Palmares (VAR-Palmares), foi presa e torturada nas dependências do DOI-CODI, em São Paulo. Bete Mendes narra que, ao descer do avião, foi recebida no aeroporto de Montevidéu por aquele que anos antes a havia torturado. Para ela, Dr. Tibiriçá, um dos apelidos do mais notório torturador do regime. Para o governo brasileiro, Cel. Brilhante Ustra, adido militar na embaixada brasileira naquele país: "Ele foi me receber no aeroporto. Foi me cumprimentar. Fez questão de se apresentar para mim. Ele já demissionado do cargo de adido militar; botou a farda de gala e foi me cumprimentar na chegada (...) aí eu gelei e ele me acompanhou todos os dias, até a saída". ${ }^{16}$

Ao retornar ao país, a atriz enviou uma carta pedindo a demissão imediata do militar ao presidente José Sarney e teve seu depoimento publicizado com grande alarde em vários jornais do país. Naquele momento, Ustra se tornava a cara pública da prática da tortura no regime militar brasileiro.

Fui sequestrada, presa e torturada nas dependências do DOI-CODI do II Exército, onde o major Brilhante Ustra (Dr. Tibiriçá) comandava sessões de choque elétrico, pau-de-arara, afogamento, além do tradicional "amaciamento" na base dos "simples" tapas, alternado com tortura psicológica. ${ }^{17}$

Há vários elementos importantes nesse episódio protagonizado pela atriz Bete Mendes, tanto sobre a situação dos militares dentro do Estado brasileiro pós-ditadura como em relação ao silenciamento dos acontecimentos ocorridos naqueles anos. A atuação de Brilhante Ustra durante a ditadura, longe de ser desconhecida, era festejada dentro dos círculos militares e de políticos conservadores do país. Estima-se que dezenas de pessoas tenham sido assassinadas nas dependências do DOI-CODI entre os anos de 1970 e 1974, período em que ele esteve à frente do órgão. ${ }^{18}$

A presença de Ustra num cargo importante fora do país, assim como sua permanência, assegurada por Leônidas Pires, então ministro do exército, numa clara desobediência à sua demissão realizada por Sarney, demonstram como o período democrático brasileiro teve início sob a forte presença dos mesmos militares que sustentaram a ditadura e que continuaram influentes nas relações de poder no comando do Estado. Suas ações, tanto antes como depois, foram asseguradas pela forma como o país encerrou o regime ditatorial, marcado pela impunidade dos diversos crimes ocorridos no período $e$ pelo esquecimento e silêncio sustentados pela Lei da Anistia. Destaca-se também a sensação de insegurança e medo impostos pela presença marcante de militares em posições estratégicas do governo logo após o encerramento do ciclo.

Nesse cenário, nossos personagens são peças chaves para compreendermos tanto as ações do Estado brasileiro no que diz respeito a não efetivação de políticas que possibilitassem a apuração de crimes cometidos no período, como também, sobre os efeitos de um processo de construção do passado que intentou negar o debate e o enfrentamento com as memórias traumáticas do período. Portanto, são fundamentais para interrogarmos em que medida as disputas em torno da ditadura militar refletem os processos de adequação da memória e esquecimento sobre o período em nossos dias.

\footnotetext{
16 Entrevista com Bete Mendes à Revista Direitos Humanos no site MHuD 20/06/2010, disponível em http://www.humanosdireitos.org/atividades/17-Bete-Mendes-e-entrevistada-pelo-MHuD.htm.

${ }^{17}$ Trecho da carta de Bete Mendes endereçada a José Sarney. Estado de São Paulo. Bete Mendes denunciou Ustra: "Fui torturada por ele". Acessado em 14/08/2018.

${ }^{18} \mathrm{Em} 2008$ o Coronel Ustra foi condenando numa ação declaratória de tortura e sequestro requerida pela família Almeida Teles, dos quais 5 membros foram presos e torturados nas dependências do DOI-CODI/SP, sob comando de Ustra.
} 


\section{Os não-ditos e os muito-ditos: Dom Paulo e Ustra e as tensões entre história e memória no cotidiano}

$\mathrm{Na}$ época da produção de seu artigo, Pollack nos trouxe um argumento interessante sobre as funções dos silêncios e esquecimentos, dos "não-ditos" como táticas de preservação da memória. Assim, essas memórias traumáticas, esses acontecimentos angustiantes ou vergonhosos eram transmitidos em redes familiares, de amigos e tradições. Em um dado momento, o silenciado vem à tona e nos deparamos com o excesso do dizível.

$\mathrm{Na}$ produção desse artigo trabalhamos com quatro matérias do jornal Folha de São Paulo, juntamente com a produção dos leitores através de comentários postados no próprio site do jornal $e$ aqueles realizados na página do periódico na rede social Facebook. Atualmente, o jornal Folha de São Paulo conta com quase seis milhões de seguidores na rede social. Embora tenha deixado de postar matérias através do aplicativo em fevereiro de $2018^{19}$, há ainda um número bastante significativo de internautas que continuam a compartilhar as matérias do jornal. As quatro matérias sobre nossos personagens ganharam uma grande repercussão, tanto no acesso no próprio site como, também, nos compartilhamentos na rede social, como pode ser observado no quadro a seguir.

\begin{tabular}{|l|l|l|}
\hline \multicolumn{1}{|c|}{ Matéria } & \multicolumn{1}{|c|}{$\begin{array}{c}\text { Repercussão no } \\
\text { site Folha }\end{array}$} & \multicolumn{1}{|c|}{$\begin{array}{c}\text { Repercussão no } \\
\text { Facebook }\end{array}$} \\
\hline $\begin{array}{l}\text { Morte de coronel Ustra confirmou sua } \\
\text { convição de que nunca seria punido. FSP } \\
\text { 15/10/2015 }\end{array}$ & $\begin{array}{l}5.400 \text { compart. } \\
45 \text { comentários }\end{array}$ & $\begin{array}{l}658 \text { reações } \\
608 \text { comentários } \\
261 \text { compartilhamentos }\end{array}$ \\
\hline $\begin{array}{l}\text { Em celebração, Brilhante Ustra é chamado } \\
\text { de herói que lutou pela }\end{array}$ & $\begin{array}{l}31.000 \text { compart. } \\
\text { Paz. FSP 17/10/2016 comentários }\end{array}$ & $\begin{array}{l}10.000 \text { reações } \\
1.500 \text { comentários } \\
1.400 \text { compartilhamentos }\end{array}$ \\
\hline \multicolumn{1}{|c|}{ Paulo Evaristo Arns participa de de } \\
$\begin{array}{l}\text { homenagem por seus 95 anos. FSP. } \\
\text { 24/10/2016 }\end{array}$ & 5 Comentários & $\begin{array}{l}\text { 926 Reações } \\
140 \text { comentários } \\
58 \text { compartilhamentos }\end{array}$ \\
\hline $\begin{array}{l}\text { Morre dom Paulo Evaristo Arns, } \\
\text { ícone progressista da igreja no } \\
\text { Brasil. FSP 14/12/2016 }\end{array}$ & 41.000 Compart. & $\begin{array}{l}6,8 \text { mil reações } \\
479 \text { comentários } \\
1,2 \text { mil compartilhamentos }\end{array}$ \\
\hline
\end{tabular}

Percebamos como em 2016 houve um aumento bastante significativo na repercussão das matérias sobre o Coronel Ustra. É preciso considerar, ainda, que tal aumento pode ser compreendido dentro do fenômeno de defesa ao intervencionismo militar, que ganhou um espaço considerável nas redes sociais entre os anos de 2016 e 2018, e para o qual o Coronel aparece como ícone. Neste sentido, os debates sobre a ditadura militar nas redes sociais são embalados pelo aumento de grupos conservadores que passam a tomar o episódio como marco significativo para as representações do passado no tempo presente. A partir disso, podemos considerar alguns aspectos importantes destacados por Pollack em relação à memória, que podem nos dar alguns indícios sobre como o tema é objeto de significações diversas em nossa sociedade.

Pollack nos apresenta três problemas relacionados às tensões da memória, silêncio e esquecimento nos processos de significação do passado por sociedades que passaram por episódios traumáticos. Assim, ele nos fala de uma memória impedida, que emerge na cena pública a partir das crises de uma memória oficial e dos processos de ressignificação do passado com a emergência de outros atores a contar suas memórias na cena pública. Neste caso, segundo Pollack, nos deparamos com um transbordamento de narrativas que até então eram proibidas. São memórias que emergem entre o ressentimento e o impedimento, e essas memórias impedidas invadem a cena pública, a tencionar disputas por esse passado. Num segundo exemplo, o autor nos apresenta uma memória que foi omitida para tornar possível a convivência com outros membros da comunidade. Deste modo, o

\footnotetext{
${ }^{19}$ O jornal Folha de São Paulo começou a postar suas matérias no Facebook através de sua página oficial em março de 2010 e deixou de publicar em fevereiro de 2018, sob o argumento que a nova política de compartilhamento da rede social, implementada em janeiro daquele ano, iriam prejudicar as postagens do jornal em favorecimento de outras publicações menores, que ganhariam mais espaço na rede a partir de então.
} 
silêncio era uma maneira de garantir a estabilidade daquela sociedade que partilhava sentimentos, como o sofrimento e a culpa. Ao tratar do caso dos judeus que voltavam para suas antigas comunidades depois da segunda guerra, Pollack destaca que silenciar era uma maneira possível de conviver, uma vez que muitos dos que tinham ficado haviam colaborado ou sido omissos com as deportações, prisões e os campos de concentração aos quais foram submetidos. Por fim, vemos o último exemplo: o silenciamento da memória pela vergonha, e novamente o ressentimento, de maneira especial, quando sujeitos se deparam com a condição de submissão, delações e outras situações humilhantes vivenciadas em suas sociedades.

Podemos tomar esses três exemplos apresentados pelo autor para tentar pensar os processos de construção da memória em nossa sociedade e compreender os motivos pelos quais, por exemplo, muitos defendem o regime militar hoje.

$\mathrm{O}$ caso da atriz Bete Mendes nos parece um exemplo bastante concreto de como as distensões do poder, ou mesmo o enfraquecimento de uma narrativa oficial, dão espaço para que outras memórias possam emergir na cena pública. Somente após 15 anos do ocorrido a atriz teve coragem de revelar publicamente sua história, exatamente quando o país vivia um novo momento político. Até ali, suas memórias circulavam entre grupos de parentes e amigos; não apenas as suas, mas de muitos outros presos e familiares de desaparecidos, que passaram a construir estratégias para que suas reivindicações fossem ouvidas.

Mas, não apenas essas memórias foram tensionadas nesse memento. Os próprios militares passaram a produzir uma "contra-memória" sobre o episódio. Por exemplo, dois anos depois do ocorrido no Uruguai, Ustra lançou o livro Rompendo o silêncio, em 1987, para responder à atriz, numa tentativa de fundar outra memória sobre sua participação nos anos de chumbo, uma vez que a rede oficial que sustentava o silenciamento sobre suas ações já não mais existia. Desta forma, a estratégia passou a ser justificá-las, como algo que foi necessário para o país, que, em sua perspectiva, estava prestes a ser dominado pelo perigo comunista.

A partir do final dos anos de 1980 e começo dos anos 1990, passamos a assistir aquilo que Pollock chama de "transbordamento" da memória sobre a ditadura em nosso país, em uma significativa produção cultural que construiu relativo consenso sobre o tema, especialmente no que diz respeito à nossa historiografia, fazendo com que muitos sujeitos, como nosso mencionado aluno, avaliem que os "vencedores" do episódio sejam exatamente aqueles que se colocaram de frente contra ele, sob o preço de violações de direitos, mortes e torturas. Na prática, foram derrotados politicamente, mas nos jogos da memória, conseguiram assumir o primeiro plano das narrativas.

Quando voltamos nosso olhar mais detidamente para as tensões e fissuras desse processo de adequação da memória em nossos dias, vemos que isso não é tão simples assim. Se, em termos acadêmicos, podemos dizer que tem se construído uma sólida reflexão sobre o período com uma clara distinção sobre os processos de efetivação da memória e da elaboração do conhecimento histórico sobre o tema, o mesmo não parece ocorrer no circuito das apropriações ordinárias de nossa sociedade.

Nos referimos aos usos do passado no cotidiano $e$ às confusões entre história e memória ensejadas nos discursos que circulam em nosso meio. A despeito da profusão de obras sobre o assunto, as apropriações de leitores em matérias a respeito da ditadura militar demonstram um grande descompasso entre essa produção $e$ a apropriação ordinária do tema no cotidiano. Há ainda um elemento que gostaríamos de ponderar, mencionado por Pollack, que parece não ocorrer entre nós: a vergonha dos participantes em crimes de violação de direitos humanos, tortura e assassinatos. Para esses atores, o ressentimento emerge exatamente pelo motivo contrário: o de não terem seus esforços em "defender a pátria" contra o "perigo comunista" reconhecidos pela história. Ao seu lado, uma nova demanda de sujeitos corrobora para tais sentimentos defendendo suas ações:

K. J. - Descanse em PAZ, Coronel. Agradecemos pelos corretivos nos Comunistas $(\ldots) .{ }^{20}$

R. S. A. - Esse cidadão não compriu (sic) com seu dever ao povo brasileiro deixou vivos lula Dilma Dirceu genuíno e toda corja do Pt e comunistas tinha que ter matado

\footnotetext{
${ }^{20}$ Comentário sobre a matéria: "Morre coronel Ustra, ex-chefe do DOI-CODI durante a ditadura". FacebooK - Folha de São Paulo 15/10/2015.
} 
todos. ${ }^{21}$

E. M. - Sempre digo o mesmo. Nossa ditadura militar foi branda. Bom foi Pinochet no Chile que exterminou os comunistas naquele país e hoje está ótimo. ${ }^{22}$

Como pode ser percebido nas falas, muitos não se constrangem em defender abertamente o assassinato e a tortura como práticas legítimas de poder aspectos que ressaltam a própria face autoritária de nossa sociedade. Neste sentido, não se trata de analisar a ordem dos discursos nas armadilhas da cronologia retrospectiva que busca a origem do verdadeiro acontecimento "que além de qualquer começo aparente há sempre uma origem secreta - tão secreta e tão originária que dela jamais poderemos nos reapoderar inteiramente" . ${ }^{23}$ Não nos referimos à simples continuidade discursiva entre o dito e não-dito, ou "jamais-dito" de "um discurso sem corpo, uma voz tão silenciosa quanto um sopro, uma escrita que não é senão o vazio de seu próprio rastro" ${ }^{24}$

No caso do nosso país, percebemos que o enfrentamento do passado criou sérios obstáculos para a construção de um pensamento reflexivo para o presente. A banalização sob a qual a violência $e$ a violação de direitos continua sendo vista entre nós corrobora não apenas para aceitação de tais práticas, mas pela solicitação delas entre nós.

Nas quatro matérias estudadas para esse artigo, produziu-se um total de 2.819 comentários. Neste total o conceito de memória foi referido apenas 14 vezes, história mencionado 63 vezes. Na maioria constata-se a desconexão entre o texto e as apropriações dos leitores, o que pode nos indicar que as matérias servem para deflagrar debates que têm como questão central posicionamentos presentes nos quais predomina uma forte polarização, mas não a leitura detida das mesmas, tampouco uma apropriação qualitativa desses conceitos. Segundo Pollack,

Conforme as circunstâncias, ocorre a emergência de certas lembranças, a ênfase é dada a um ou outro aspecto. Sobretudo a lembrança de guerras ou de grandes convulsões internas remete sempre ao presente, deformando e reinterpretando o passado. Assim também, há uma permanente interação entre o vivido, o aprendido $e$ o transmitido. ${ }^{25}$

Embora isso ocorra, é preciso também ler tal elemento como um sintoma da maneira como o brasileiro lida com essas questões. No meio da disputa, as confusões entre história, memória, conhecimento e opinião ganham contornos dramáticos e servem para acirrar posições nas quais emergem as reivindicações de cada um dos lados para que a "verdadeira" história seja desvelada: Vejamos as falas de alguns internautas ao se referirem à morte do Cel. Ustra.

L. Santana - Grande nas suas atitudes! Sou a favor do regime militar, sempre fui. E meus caros, não venham comentar que não sei história, pois a conheço muito bem. Mas também sei que a mesma sempre foi e sempre será manipuladora. ${ }^{26}$

T Teodoro - Mais um que foi com a verdadeira história brasileira. ${ }^{27}$

Os comentários nos ajudam a entender como os discursos vão estabelecendo procedimentos de controle uns sobre os outros de forma hierarquizada, mais do que isso. Podemos perceber as disputas em torno da narrativa histórica, que embora seja colocada em dúvida sobre suas conclusões, é para ela que as falas se direcionam para marcar o lugar de Ustra dentro dela. Mas constata-se também como a sua compreensão se aproxima de uma definição de memória, uma vez que a "verdadeira história" morreria junto com o sujeito que poderia narrá-la. Em que pese o ensino de história como disciplina escolar ter feito todo um esforço entre as décadas de 1990 e 2010 de construção de reflexão crítica sobre seus conteúdos, o que podemos observar é que não foi capaz de vencer a defesa do Golpe

\footnotetext{
${ }^{21}$ Comentário sobre a matéria: Morre coronel Ustra...

${ }^{22}$ Comentário sobre a matéria: Morre coronel Ustra...

${ }^{23}$ FOUCAULT, Michel. A arqueologia do saber. Rio de Janeiro: Forense Universitária, 2016, p. 30.

${ }^{24}$ FOUCAULT, Michel. A arqueologia do saber...

${ }^{25}$ POLLACK, Micheal. Memória, Silêncio e Esquecimento..., p. 3-15.

${ }^{26}$ Comentário sobre a matéria: Morre coronel Ustra...

${ }^{27}$ Comentário sobre a matéria: Morre coronel Ustra...

260 SÆCUluM - Revista DE HistóRIa [39]; João Pessoa, jul./dez. 2018.
} 
Militar como uma medida preventiva contra o "perigo comunista". No atual momento, de retorno conservador, muitos que passaram pelos bancos escolares nesse período repetem discurso muito próximo de 1964.

Há, portanto, um conjunto de enunciados provindos de uma mesma formação discursiva que sobreviveu à espessura de mais de cinquenta anos e que conseguiu reemergir nos tempos atuais, ampliado pelas redes sociais. Uma permanência argumentativa entre os comentários nas reportagens citadas é, por exemplo, ver as justificativas do General Presidente Médici ${ }^{28}$ sobre a ação das forças armadas nos anos de 1960 e 1970 como uma necessidade para interromper o avanço:

- da ameaça crescente às liberdades básicas dos indivíduos e da sociedade;

- da perturbação e subversão da ordem social, econômica e moral;

- da degenerescência dos costumes, invadindo as escolas, os lares, os campos, as oficinas e os templos religiosos;

- do aviltamento dos mais sagrados fundamentos que sustentam a Nação, quais sejam a família, o trabalho, a produção, a moral cristã, a cultura, a arte, a autoridade dos pais e dos mestres, a autoridade do Governo e dos chefes militares;

- da usurpação da consciência e da coragem moral dos homens.

Percebamos como, na fala do General, são elencados elementos muito próximos daqueles ensejados por leitores mais de 50 anos depois do Golpe de 1964. Em relação à matéria sobre a morte do Coronel Ustra, de 15 de outubro de 2015, assistimos à repetição sobre a ameaça comunista e em defesa da moral e dos bons costumes, vejamos:

H. Rabelo - (...) Che Guevara foi TORTURADOR (sic) e você defende essa laia de esquerdopatas que mataram, torturaram, explodiram e roubaram em nome do Comunismo? (sic) Regime que tentaram (sic) implantar aqui em 64. Graças aos militares esses golpistas não transformaram o Brasil numa Cuba. ${ }^{29}$

L. Saraiva - O Brasil das pessoas de bem, corretas, honestas, éticas, que trabalham e verdadeiramente sustentam e mantém esse país, consternado, agradece pelos bons serviços prestados. É uma perda irreparável. Sentimentos à família enlutada. Descanse em paz. ${ }^{30}$

Percebe-se, assim, uma convergência discursiva predominante entre os grupos conservadores brasileiros ao longo do século XX, fundada numa matriz anticomunista acionada em vários momentos de crise. Rodrigo Patto Sá Motta chama atenção para o fato de que, apesar da heterogeneidade desses grupos, o "(...) anticomunismo tornou-se uma força decisiva nas lutas políticas do mundo contemporâneo, alimentado e estimulado pela dinâmica do inimigo que era sua razão de ser, o comunismo". ${ }^{31}$

No entanto, mais do que perceber essa recorrência, é preciso identificar as superfícies de emergência nas quais esses conceitos e temas são constituídos e ganham espaços. Essas superfícies se dão nos grupos sociais normativos mais próximos, como a família, o trabalho, a escola, ou nas comunidades religiosas.

Entre a última década do século XX e a primeira do século XXI, os avanços democráticos estabeleceram filtros que dificultavam os discursos de ódio ao comunismo e aos grupos sociais historicamente excluídos quando se tratava de discursos públicos de defesa de uma determinada moral cristã e sua proposta de família, arte, ciência, produção e trabalho. No entanto, de maneira sub-reptícia

\footnotetext{
28 "A Nova Consciência de Brasil”. Discurso proferido por Médici na Vila Militar, por ocasião do aniversário de Monte Castelo, em 21-2-1970, p. 27. Trata-se de uma coletânea dos primeiros discursos do Presidente Emílio Garrastazu Médici, após suceder ao Costa e Silva, feita pela equipe da Secretaria de Imprensa e da Assessoria Especial de Relações Públicas da Presidência da República, em uma coletânea intitulada O Jogo da Verdade.

${ }^{29}$ Comentário sobre a matéria: Morre coronel Ustra...

${ }^{30}$ Comentário sobre a matéria: Morre coronel Ustra...

${ }^{31}$ MOTTA, Rodrigo Patto Sá. Em guarda contra o perigo vermelho: o anticomunismo no Brasil. Tese de Doutorado Faculdade de Filosofia, Letras e Ciências Humanas da USP. 2000, p. 5.
} 
podemos dizer que havia uma série de não-ditos a sustentar padrões do autoritarismo que, se não eram dominantes, conseguiram preservar muitos desses referentes de ação. $\mathrm{O}$ que pode ser percebido é que, a partir de 2013, esses filtros foram sendo rompidos e antigas representações sobre o passado recente foram solicitadas; não por acaso, observamos a reedição de paradigmas de compreensão sobre os significados da ditadura militar para o país.

É assim que se pode compreender porque Dom Paulo Evaristo Arns, ícone da resistência ao regime, que ganhou diversos epítetos, como os destacados na própria reportagem da Folha de São Paulo, de 27/06/2018 - "(...) cardeal da liberdade, bispo dos oprimidos, (...), cardeal da cidadania, guardião dos direitos humanos e tantos outros" - é atacado em comentários sob os mesmos elementos argumentativos.

J. A. B. Filho - O cardeal Arns, o preferido dos comunistas, defendeu Leonardo Boff, teve a gratidão manifesta de João Pedro Stédile, e nutria admiração por Fidel Castro. $^{32}$

P.A. Figueiredo - O único pecado capital cometido por este senhor foi empunhar bandeiras comunistas. ${ }^{33}$

E. R. N. Viciana - Lutou contra o regime militar, aquela quase ditadura de centro que não proibia nada, enquanto articulava politicamente outra ditadura, a comunista bolivariana. $^{34}$

Em que pesem os comentários elogiosos ao Cardeal e em sua defesa na mesma matéria, como o depoimento emocionado da leitora: "Morreu o campeão dos direitos humanos do Brasil, um pastor digno, dos poucos que se opôs aos desmandos da ditadura militar, como ex-presos políticos devemos muito da nossa integridade na época à ação do Dom Paulo, a quem seremos eternamente gratos" ${ }^{35}$

É possível identificar entre aqueles que atacam sua imagem a mesma dicotomia de uma realidade pautada na simplificação conceitual entre o bem e o mal, comunistas contra não comunistas. É certo que há um embate entre os defensores tanto de um, como de outro personagem. Em termos numéricos, a reportagem sobre a morte de Dom Paulo na Folha teve uma repercussão 10 vezes maior do que a do Coronel Ustra. Para termos uma ideia, a partir do site do jornal, a notícia da morte de Dom Paulo, ocorrida em 2016, foi compartilhada 41 mil vezes, contra 5,1 mil do Coronel Ustra em 2015. Mas aqui chamamos a atenção para um aspecto relevante: em 2016, quando Ustra foi homenageado em missa de um ano de falecimento, sendo chamando pelo padre celebrante de "herói que lutou pela paz", a repercussão da matéria praticamente se igualou àquela sobre a morte de Dom Paulo: 31 mil compartilhamentos na página do jornal, além disso, como pode ser observado na tabela que apresentamos anteriormente, a mobilização na página do Facebook supera aquelas relacionadas a Dom Paulo.

A observação desses elementos nos dá indícios sobre como as sensibilidades em relação ao episódio da ditadura militar brasileira se modificaram rapidamente nessa esfera pública. Se até 2013 parece ainda se sustentar boa parte daqueles filtros que impediam a emergência de posturas extremadas e conservadoras sobre o tema, a partir de 2016 esse cenário se deteriora enormemente.

Uma significativa parte dos comentários favoráveis ao regime militar é feita exatamente por leitores que têm curso superior, estão empregados e pertencem aos vários estados da federação. Num levantamento inicial foram constatados leitores de 20 estados, sendo a maior parte deles do Rio de Janeiro e de São Paulo. Na maioria dos comentários nos quais a história é exaltada, há uma clara polarização entre uma história falsa, deturpada, que possivelmente teria sido escrita pela esquerda, $e$ uma outra história, a verdadeira, a qual deve ser a todo custo revelada. ${ }^{36}$

\footnotetext{
${ }^{32}$ Comentário sobre a matéria "Morre dom Paulo Evaristo Arns, ícone progressista da igreja no Brasil". Folha de São Paulo, 14/12/2016.

${ }^{33}$ Comentário sobre a matéria Morre dom Paulo Evaristo Arns...

${ }^{34}$ Comentário sobre a matéria Morre dom Paulo Evaristo Arns...

${ }^{35}$ C. e A. Schoenacker. Folha de São Paulo. 14/12/2016.

${ }^{36}$ Esses dados são levantados por amostragem. Por exemplo, tomamos como referente entre $5 \%$ a $10 \%$ de comentários em cada matéria; a partir deles são verificados os perfis dos autores, afim de dirimir dúvidas quanto à veracidade dos perfis, se são legítimos ou "fakes", apenas para criar interação nas páginas. A partir disso, verifica-se os elementos que indicam publicamente profissão, escolaridade, região de onde falam, etc.
} 
Para Koselleck ${ }^{37}$ essa crença em uma verdade história a ser revelada faz parte de um topos que parece ter permanecido durante longo tempo como cânone da escrita histórica e, não por acaso, se difundiu em outras escrituras e formas de pensamento sobre o passado. Por conseguinte, parece bastante pertinente que, para pensarmos essas apropriações da história por nossos leitores, consideremos que:

Permaneceu intacta a precedência dada ao registro da história contemporânea acrescida da contribuição dada, nos inícios da época moderna, pela literatura memorialista. E assim permaneceu também quando a investigação estendeu-se ao passado imediato. Os índices de verossimilhança permaneceram associados ao testemunho ocular, e, se possível, ao de agentes e participantes, seja no que diz respeito à história da Revelação, seja nas histórias dos eventos eclesiais ou mundanos. ${ }^{38}$

Isso explica o fato de encontrarmos tantos depoimentos recorrendo aos pais, avós, para falar sobre o período, numa idealização do passado ditatorial como tempo tranquilo de abundância e paz que só pode ser narrado por quem o viveu, o que funcionaria como antídoto contra a história crítica, escolar ou acadêmica. Como observamos na fala da leitora abaixo:

C. S. - Boa tarde a todos... Esta senhora ak hj, mãe e avó, cresceu, estudou se formou, casou e formou uma família no período dos governos dos militares....... Tenho saudades, pq tínhamos segurança, o direito de ir e voltar sem nada acontecer, sem bandidos assaltantes e sequestradores pelas ruas, só quem vivenciou sabe realmente o q aconteceu, vejo histórias distorcidas, q eram torturadores, isto ou aquilo e rigorosos sim, mas c os guerrilheiros q queriam implantar o comunismo no Brasil a todo custo, e devemos sim muito a eles pq se $\mathrm{n}$ lutassem $\mathrm{c}$ unhas e dentes, hj seriamos Cuba!! ${ }^{39}$

Ou seja, são pessoas que ocupam redes de comunicações privilegiadas, emitem e recebem informações, ao mesmo tempo em que questionam, conforme vão se formando as grades discursivas que têm início nas reportagens e que se ampliam em comentários que ganham espaço nas redes sociais. Neste sentido, podemos falar em uma teia de informações que se torna cada vez mais complexa e se arraiga entre os sujeitos dessa sociedade. Nesse sistema de comunicação, emissores $e$ receptores de conteúdos e opiniões vão se redefinindo e se retroalimentam das informações trocadas nesses espaços, tornando-se cada vez mais difícil definir sua identificação de origem, seus domínios e grupos.

Estas enunciações discursivas em defesa ou contra a ditadura militar e os que protagonizaram o período, de um lado ou de outro, ainda que guardem certa unidade, dispersam-se nos meios e lugares por onde circulam. Longe de se justaporem, são enunciações que se alimentam nesse feixe de relações discursivas a partir dos lugares de pronunciamento.

Nesse universo, evidencia-se o papel da Internet como recurso de tradução, leitura e produção de novos sentidos na contemporaneidade. Aspecto que acabou por atingir também os registros sobre o passado, na medida em que os chamados acontecimentos emblemáticos são fortes referentes de disputas, debates e discursos no mundo virtual. Todavia, é preciso considerar que esses novos sujeitos da informação nem são "indivíduos soberanos, nem massas uniformes" ${ }^{40}$ Para Canclini,

(...) os públicos não nascem, mas se formam, porém de modo diverso, quer se trate da era de Gutemberg, ou da digital. (...) Condicionamentos parecidos não geram comportamentos semelhantes em pessoas que se socializam na leitura durante a época da televisão ou na Internet. Isso se refere também aos leitores de jornais $e$ internautas. ${ }^{41}$

\footnotetext{
${ }^{37}$ KOSELLECK, Reinhart. Futuro Passado - contribuição à semântica dos tempos históricos. Rio de Janeiro: PUC, 2006.

${ }^{38}$ KOSELLECK, Reinhart. Futuro Passado..., p. 66.

${ }^{39}$ Comentário postado sobre a matéria: "Em celebração, Brilhante Ustra é chamado de herói que lutou pela Paz". Facebook Folha de São Paulo, 17/10/2016.

${ }^{40}$ CANCLINI, Néstor Garcia. Leitores, Espectadores e Internautas. São Paulo, Ed. Iluminuras. 2008. p.16

${ }^{41}$ CANCLINI, Leitores, Espectadores e Internautas...
} 
Para voltarmos ao início deste artigo, quando dialogamos com Pollack, talvez estejamos a assistir novas configurações da memória dispersa nesse confuso universo virtual, para qual o passado $e$ o presente se misturam de maneira desconcertantes. Agora, também o julgamento do passado e de seus sujeitos se situa nas conversas de redes sociais e em sites de notícia. Aspectos bastantes preocupantes, porque submetem a complexidade da construção das memórias, dos esquecimentos e da própria história às pressões de um hiperpresente. É a partir dele, e de todos os seus vícios de compreensão, influenciados em grande parte pelas emoções, que esse passado tem sido posto em disputa. 


\section{RESUMO}

Este artigo pretende discutir as tensões na construção de memória e esquecimento no Brasil sobre dois personagens emblemáticos no período da ditatura militar brasileira recente: Dom Paulo Evaristo Arns e o Cel. Brilhante Ustra. A partir da análise de matérias do Jornal Folha de São Paulo sobre suas mortes e homenagens prestadas, investiga-se as apropriações de leitores sobre as mesmas, coloca-se em relevo formas de leituras do passado, as permanências de discursos conservadores em nossa sociedade $e$ as dificuldades com as quais os leitores lidam com as representações do passado em seu cotidiano.

Palavras-chaves: Ditadura militar; Dom Paulo Evaristo Arns; Ustra; História; Memória.

\begin{abstract}
This article intends to discuss the tensions in the construction of memory and forgetfulness in Brazil about two emblematic characters in the period of the recent Brazilian military dictatorship: Dom Paulo Evaristo Arns and Cel. Brilhante Ustra. Based on the analysis of Folha de São Paulo newspaper about their deaths and tributes, the reader's appropriations are investigated, as well as the forms of reading from the past, the preservation of conservative discourses in our society and the difficulties which readers deal with representations of the past in their daily lives.
\end{abstract}

Key-words: Military dictatorship; Dom Paulo Evaristo Arns; Ustra; History; Memory.

Artigo recebido em 07 ago. 2018.

Aprovado em 14 set. 2018. 
